\title{
Small Intestinal Phosphate Absorption: Novel Therapeutic Implications
}

\author{
Jerry Yee ${ }^{a}$ David Rosenbaum ${ }^{b}$ Jeffrey W. Jacobs ${ }^{b}$ Stuart M. Sprague ${ }^{c}$ \\ ${ }^{a}$ Nephrology and Hypertension, Henry Ford Hospital, Detroit, MI, USA; ${ }^{b}$ Ardelyx, Inc., Boston, MA, USA; 'Division of \\ Nephrology and Hypertension, NorthShore University Health System, Evanston, IL, USA
}

\section{Keywords}

Chronic kidney disease · Hyperphosphatemia · Paracellular phosphate absorption - Transcellular phosphate absorption . Tenapanor

\begin{abstract}
Background: Chronic kidney disease (CKD) affects approximately $15 \%$ of adults in the USA. As CKD progresses, urinary phosphate excretion decreases and results in phosphate retention and, eventually, hyperphosphatemia. As hyperphosphatemia is associated with numerous adverse outcomes, including increased cardiovascular mortality, reduction in phosphorus concentrations is a guideline-recommended, established clinical practice. Dietary phosphate restriction, dialysis, and phosphate binders are currently the only options for phosphate management. However, many patients with hyperphosphatemia have phosphorus concentrations $>5.5 \mathrm{mg} / \mathrm{dL}$, despite treatment. Summary: This review presents recent advances in the understanding of intestinal phosphate absorption and therapeutic implications. Dietary phosphate is absorbed in the intestine through two distinct pathways, paracellular absorption and transcellular transport. Recent evidence indicates that the paracellular route accounts for $65-80 \%$ of total phosphate absorbed. Thus, the paracellular pathway is the dominant mechanism of phos-
\end{abstract}

phate absorption. Tenapanor is a first-in-class, non-phosphate binder that inhibits the sodium-hydrogen exchanger 3 or solute carrier family 9 member 3 (SLC9A3) encoded by the SLC9A3 gene, and blocks paracellular phosphate absorption. Key Messages: Targeted inhibition of sodium-hydrogen exchanger 3 effectively reduces paracellular permeability of phosphate. Novel therapies that target the paracellular pathway may improve phosphate control in chronic kidney disease.

(C) 2021 The Author(s)

Published by S. Karger AG, Basel

\section{Biological Role and Sources of Phosphate}

Phosphorus is one of the most abundant minerals in the body $[1,2]$. Approximately $85 \%$ of total body phosphorus is skeletal and the remaining $15 \%$ is in soft tissues [1]. Almost all of the phosphorus found in the extracellular fluid space is in the form of inorganic phosphate [1]. Proper functioning of many biological processes, including cellular energy production, release of oxygen to the peripheral tissue by red blood cells, and bone mineralization, requires normal phosphate concentrations [1]. Although orthophosphate primarily circulates in plasma as $\mathrm{H}_{2} \mathrm{PO}_{4}{ }^{2-}$ and $\mathrm{HPO}_{4}{ }^{-}$(4:1 ratio) [1], a small proportion forms complexes with calcium and magnesium ions [3].
C 2021 The Author(s).

Published by S. Karger AG, Basel

This is an Open Access article licensed under the Creative Commons Attribution-NonCommercial-4.0 International License (CC BY-NC) (http://www.karger.com/Services/OpenAccessLicense), applicable to the online version of the article only. Usage and distribution for commercial purposes requires written permission.
Correspondence to:

Jerry Yee, jyee1@hfhs.org 
Laboratory measurement of orthophosphate is reported as serum phosphorus [4], with a normal range of 2.5-4.5 $\mathrm{mg} / \mathrm{dL}$ [5].

Dietary phosphate ingestion is the primary source of phosphorus intake [6]. Plant-based phosphate is primarily in the form of phytate (6-fold dihydrogen phosphate ester of inositol) and is concentrated in whole grain cereals and legumes $[7,8]$. Because humans lack the enzyme phytase, there is minimal to no phytate degradation in the small intestine, accounting for the low bioavailability of plant-based dietary phosphate [9]. Phytates are considered by some experts to be "anti-nutritional factors" due to their ability to prevent absorption of minerals $[10,11]$, and the phytase enzyme is sometimes added to processed food products to increase the bioavailability of minerals [12]. There is evidence to suggest that phosphate from animal-based sources such as meat or fish may be more bioavailable than phosphate from plant-based sources [13]. In a 1-week study, a primarily plant-based diet led to lower phosphorus concentrations than a primarily animal-based diet containing the same quantity of phosphate [13]. This may have been due to the lower bioavailability of phytate-bound phosphorus in comparison to animal-based sources and/or the additional strain on the kidney from higher availability of protein in meat-based diets [13]. Therefore, the source of dietary phosphate (animal-based vs. plant-based) influences phosphorus management [13].

Modern food processing has significantly increased the quantity of dietary phosphate intake. The inclusion of processed foods is estimated to increase daily dietary phosphorus intake by approximately $1,000 \mathrm{mg}[14,15]$. However, as food manufacturers are not required to list the quantity of phosphorus in their food additives, the actual quantity of dietary phosphorus from food additives may easily supersede the estimated intake of $1,000 \mathrm{mg}$ $[16,17]$. In addition, food additives are mostly inorganic phosphate, which are believed to be more readily and completely absorbed in humans compared to organic phosphates [14].

A conventional Western diet contains a significant proportion of processed foods $[15,18]$, which often contain unknown quantities of phosphate additives $[15,19]$. The normal daily phosphorus intake is estimated at $>2,500 \mathrm{mg}[14,20,21]$. This intake is $>3$-fold greater than the recommended daily allowance of approximately 700 $\mathrm{mg}$ [22]. Consequently, although patients with end-stage renal disease (ESRD) should adhere to low phosphorus diets of $<1,000 \mathrm{mg}$ daily [23], numerous phosphate additives may lead to an intake of much greater quantities of phosphorus than appreciated [14]. Phosphate excipients (e.g., anhydrous calcium hydrogen phosphate) commonly accompany medications prescribed for dialysis-dependent chronic kidney disease (CKD) patients, and excipients may contribute $100-200 \mathrm{mg}$ of phosphorus to the daily load $[24,25]$. Therefore, the daily phosphorus intake may approach 2,500 $\mathrm{mg}$. Of this quantity, approximately $60-80 \%$ would be absorbed by the gastrointestinal tract [26].

\section{Phosphate Regulation and Negative Impact of Hyperphosphatemia in CKD}

CKD is estimated to affect $15 \%$ of adults in the USA [27]. As CKD progresses, urinary phosphate excretion decreases and phosphate retention occurs [28]. Phosphate homeostasis is regulated by 3 hormones: parathyroid hormone $(\mathrm{PTH})$, fibroblast growth factor-23 (FGF23), and active vitamin D in the form of calcitriol (1,25-dihydroxycholecalciferol) [29]. Calcitriol increases active intestinal phosphate transport by increasing expression of the transporters PiT-2 and NaPi2b [30-32], whereas PTH and FGF23 work to decrease phosphate concentrations [29]. In the early stages of CKD, PTH and FGF23 concentrations increase as compensatory mechanisms [33-35]. These mechanisms enhance renal phosphate excretion and decrease intestinal phosphate absorption to maintain serum phosphorus concentrations within the normal range [33-35]. Vitamin D receptordependent decreases in intestinal transcellular phosphate transport as a result of compensatory mechanisms have been observed in animal models [35]. Phosphorus concentrations are stable in early CKD stages before increasing in later stages, but FGF23 and PTH increase steadily and significantly as the disease progresses, suggesting that these mechanisms are eventually insufficient to maintain phosphate homeostasis [33]. Consequently, $>80 \%$ of patients with ESRD require treatment for hyperphosphatemia [36].

Hyperphosphatemia is associated with several adverse outcomes (e.g., vascular calcification, cardiovascular (CVD) disease, and secondary hyperparathyroidism) [37-39]. Phosphate retention is considered the initiating and driving force of the mineral and endocrine disruptions that comprise CKD-mineral bone disorder [40], a common complication in patients with CKD associated with CV morbidity and mortality [41-43]. Phosphate retention also triggers an increase in FGF23 and PTH concentrations, both of which have been suggested to have 
Fig. 1. Dietary phosphorus absorption occurs in the small intestine via 2 distinct pathways: transcellular and paracellular. The transcellular pathway is characterized by active intestinal phosphate transport that occurs primarily through the action of the NaPi2b. Maximum absorption via the transcellular pathway is achieved at luminal phosphorus concentrations of approximately $6.0 \mathrm{mg} / \mathrm{dL}$ (2 mmol/L). Paracellular phosphate absorption occurs passively along concentration gradients through tight junction complexes (e.g., claudins and occludins) between cell membranes. The mechanism of the paracellular phosphate absorption is consistent with nonsaturable, passive diffusion, which constitutes the majority of intestinal phosphorus absorption in humans. NaPi2b, sodium-dependent phosphate cotransporter $2 \mathrm{~b}$.

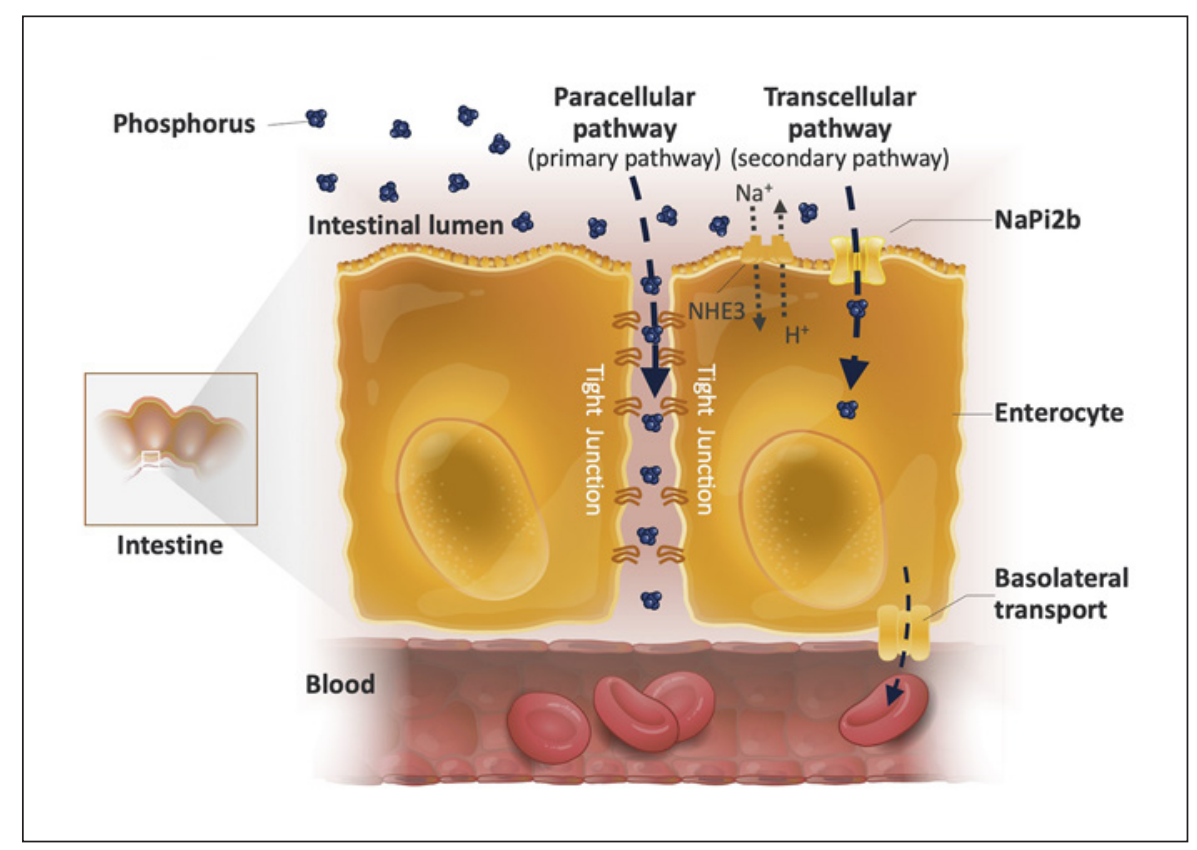

direct pathogenic CV effects $[44,45]$. Hyperphosphatemia is also an independent risk factor for CV mortality, the primary cause of death in patients with CKD [27, 46, 47]. Kestenbaum et al. [48] found that each $1 \mathrm{mg} / \mathrm{dL}$ increase in serum phosphorus was associated with $~ 23 \%$ increased mortality risk. Phosphorus concentrations of $4.5-4.9 \mathrm{mg} / \mathrm{dL}$ were associated with greater hazard ratios than concentrations of $4-4.5 \mathrm{mg} / \mathrm{dL}$ (1.93 vs. 1.34) [48]. Phosphorus concentrations greater than $3.5 \mathrm{mg} / \mathrm{dL}$ have also been shown to increase mortality risk in both adults with and without CKD $[48,49]$, confirming that even increases within normal concentrations $(2.5-4.5 \mathrm{mg} / \mathrm{dL})$ negatively impact health outcomes. Improved patient survival is associated with serum phosphorus concentrations that do not exceed $4.5 \mathrm{mg} / \mathrm{dL}$ [50].

Because of the negative consequences of hyperphosphatemia, reduction in phosphorus, with the goal of maintaining concentrations toward the normal range, is a guidelinerecommended, established clinical practice [23, 51]. However, achieving proper phosphorus control remains a clinical challenge, and many patients with CKD have phosphorus concentrations exceeding $5.5 \mathrm{mg} / \mathrm{dL}$ [52]. The development of strategies and treatments guided by an understanding of the pathogenesis of hyperphosphatemia and underlying physiology of phosphate absorption can potentially improve our ability to manage phosphorus concentrations and improve clinical outcomes.

\section{Advances in Phosphate Absorption and Regulation Mechanisms}

Serum phosphorus concentrations are balanced through intestinal uptake, retention or by release from bone, and regulation of renal phosphate reabsorption [53-55]. Phosphate from dietary sources travels through the gut and becomes available for intestinal absorption [55].

Dietary phosphate absorption occurs in the small intestine via 2 distinct pathways: the saturable transcellular pathway involving specific phosphate transporters and the nonsaturable paracellular pathway driven by the phosphate concentration gradient (Fig. 1) [55-58]. Classically, the transcellular pathway was considered the primary mechanism of phosphate absorption [53]. Animal studies of the transcellular pathway document that active intestinal phosphate transport occurs primarily via the sodium-dependent phosphate cotransporter $2 \mathrm{~b}$ (NaPi2b) [59]. Maximum absorption via the transcellular pathway is achieved at luminal concentrations of approximately $6.0 \mathrm{mg} / \mathrm{dL}$ phosphorus $(2 \mathrm{mmol} / \mathrm{L})$ in patients with ESRD [58]. Based on published data describing gastric volume, a typical Western diet containing $2,500 \mathrm{mg}$ of phosphorus per day would produce luminal phosphorus concentrations of approximately 55-110 $\mathrm{mg} / \mathrm{dL}(18-36 \mathrm{mmol} / \mathrm{L})[6,14,60]$, which greatly exceeds the transport maximum of the transcellular pathway. Experimental evidence from ESRD patients sug- 
gests that $\mathrm{NaPi} 2 \mathrm{~b}$ is more important for phosphate absorption when luminal phosphate concentrations are low [58], as might occur during dietary privation. The minor role for transcellular absorption in humans is supported by divergent results from NaPi2b inhibitor trials in animals and humans. In animal trials, serum phosphorus concentrations were reduced, consistent with the hypothesis that transcellular transport was the prime mediator of intestinal phosphate absorption [61]. These studies are often performed with diets that favor the transcellular pathway and are not reflective of human phosphorus consumption. In humans, a phase 1 trial of a NaPi2b inhibitor found no changes in phosphorus concentrations of healthy volunteers or hyperphosphatemic patients with ESRD who were administered single (10 or $100 \mathrm{mg}$ ) or multiple $(10,30$, or 100 mg 3 times per day) doses [62]. The transcellular pathway is not the primary modality of intestinal phosphate absorption in humans $[62,63]$.

Human and animal models have shown that paracellular phosphate absorption occurs passively along concentration gradients through tight junction complexes (e.g., claudins and occludins) between cell membranes $[58,64-66]$. The human concentration gradient is subject to dietary intake and the bioavailability of phosphate sources $[58,67]$. Under normal dietary conditions, human and animal models have established that the paracellular route is nonsaturable and responsible for the majority of intestinal phosphate absorption, particularly when phosphate concentrations are high [58, 64]. Animal models indicate that paracellular absorption constitutes about $65-80 \%$ of intestinal phosphate absorption and transcellular absorption is $20-35 \%[68,69]$. Because of the relatively high luminal phosphate concentrations associated with modern diets and the lack of a saturation "limit," the paracellular route is responsible for a much greater proportion of phosphate absorption than the transcellular route $[58,65]$.

Intestinal epithelial permeability of phosphate through the paracellular pathway appears to be influenced by the sodium-hydrogen exchanger 3 (NHE3), which is expressed throughout the human gastrointestinal tract and more highly expressed in the small intestine $[66,70]$. Regulation of NHE3 is achieved both acutely and chronically [71]. In animal and in vitro models of human small intestinal enteroids, NHE3 inhibition increases transepithelial electrical resistance [66]. In the absence of an obvious signaling pathway or tight junction protein trafficking, the rapid increase in transepithelial electrical resistance suggests that a direct $\mathrm{pH}$-sensitive conforma-

Small Intestinal Phosphate Absorption tional change to the tight junction proteins (e.g., claudins) reduces paracellular phosphate permeability [66]. The effects of NHE3 inhibition were evaluated in NHE3knockout mice, created by disrupting the solute carrier family 9 member 3 gene [72-74], and in animal trials of a targeted NHE3 inhibitor [75]. These studies uniformly demonstrated reduced intestinal phosphate, sodium, and water absorption [72-75]. These results have subsequently been confirmed in clinical trials of an NHE3 inhibitor in healthy volunteers and patients with ESRD. In both groups, a dose-dependent inhibition of intestinal phosphorus absorption was evident, resulting in decreased serum phosphorus in patients with ESRD [66, $76,77]$. Collectively, the paracellular phosphate absorption pathway is diminished by enterocyte inhibition of NHE3.

\section{Challenges of Current Phosphate Management in Patients with CKD}

Phosphorus management for patients with CKD currently consists of a three-pronged approach: restricting dietary phosphate intake, reducing intestinal phosphate absorption with phosphate binders, and enhancing phosphate elimination with dialysis [78]. A conventional hemodialysis session can remove up to $1,000 \mathrm{mg}$ of phosphorus [79]. The efficacy of dialysis is limited by the small amount of phosphate present in the readily accessible plasma space [80]. Following removal of plasma phosphate, further removal is regulated by the rate-limiting step of phosphate translocation from the intracellular pool to plasma [80]. While dietary phosphate restriction and phosphate removal by dialysis are important, these maneuvers do not consistently achieve and/or maintain appropriate phosphorus control [81]. For hemodialysis patients with persistent hyperphosphatemia, there is lowquality evidence that monthly dietary therapy represents effective therapy [82].

Controlling serum phosphorus through dietary interventions (low phosphorus diet) is a key component of hyperphosphatemia management but brings challenges with adherence as well as maintaining adequate nutrition. For example, there is a strong correlation between dietary phosphate and protein intake [83]. As a corollary, dietary phosphate restriction may place patients at risk for inadequate protein intake [84]. Patients with advanced CKD are at substantial risk for malnutrition, characterized by protein-energy wasting and low energy intake, that increases risk of morbidity and mortality $[85,86]$. 


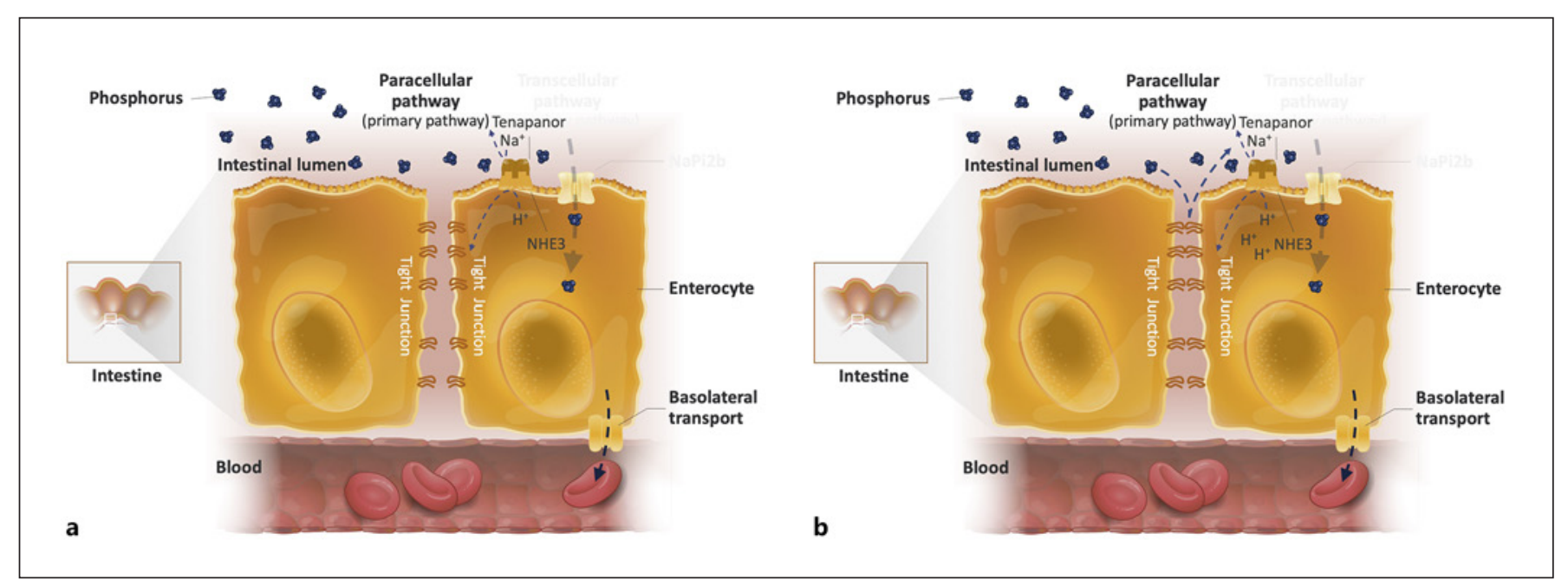

Fig. 2. Tenapanor, a specific, investigational NHE3 inhibitor, produces a modest intracellular proton retention that is proposed to induce conformational change(s) in claudin proteins present in tight junctions, thereby reducing paracellular phosphate transport. NHE3, sodium-hydrogen exchanger 3.

Phosphate binders are prescribed to $>80 \%$ of patients on dialysis and are the only pharmacological treatment currently indicated for hyperphosphatemia [36]. These agents form complex dietary phosphates in the intestinal lumen and form insoluble complexes that are excreted [87-91]. However, the administration of phosphate binders as a class generally does not achieve and maintain phosphorus concentrations $<5.5 \mathrm{mg} / \mathrm{dL}$ [92]. The mechanism of action of phosphate binders is inherently inefficient and provides a potential explanation for the challenges that patients and clinicians face in achieving target serum phosphorus concentrations. Nonspecific binding to ligands other than phosphate results in suboptimal efficacy and drug-drug interactions with medications commonly prescribed to patients on dialysis [87$91,93]$. Also, the short duration of action of phosphate binders require binders to be taken with meals and snacks [87-91]. The limited per pill phosphate binding capacity mandates the ingestion of multiple pills, many that are large in size [26, 94-101]. Despite phosphate binder therapy, recent data demonstrate that $42 \%$ of patients on dialysis had phosphorus concentrations $>5.5 \mathrm{mg} / \mathrm{dL}, 77 \%$ were $>4.5 \mathrm{mg} / \mathrm{dL}$ in the most recent month, and $77 \%$ were unable to consistently maintain phosphorus concentrations $<5.5 \mathrm{mg} / \mathrm{dL}$ over a 6 -month period [92], reinforcing the notion that current therapies, even when properly implemented, are insufficient to manage hyperphosphatemia.

\section{New Targeted Therapies for Hyperphosphatemia}

Given the growing evidence that the principal mode of small intestinal phosphate absorption takes place via the paracellular pathway, new therapies targeting this pathway have been investigated. Tenapanor, an investigational, first-in-class non-phosphate absorption inhibitor, targets the paracellular pathway via inhibition of enteric NHE3 (Fig. 2) [66]. In rodents and in experiments using human stem cell-derived enteroid monolayers, inhibition of NHE3 produces intracellular acidification. This change in $\mathrm{pH}$ is proposed to produce a subsequent conformational change in tight junction proteins, such as claudins or occludins, which limit paracellular phosphate transit from lumen-to-plasma [66]. By interrupting phosphate absorption, tenapanor directly and efficiently reduces serum phosphorus concentrations [77].

Tenapanor was initially approved for treatment of irritable bowel syndrome with constipation (IBS-C) in 2019 , and trial safety data for this indication adds support to the safety data generated in patients with hyperphosphatemia. In phase 1 trials of healthy volunteers, reduced intestinal phosphate and sodium absorption and enhanced intestinal fluid volume were documented without deleterious effect on serum potassium concentrations $[76,102]$. Likewise, there were no clinically significant alterations of serum sodium concentrations from baseline in a phase 2 study of IBS-C [103]. Diarrhea was the most common adverse event in the phase $2(9 \%)$ 
and phase 3 IBS-C trials (16\%) [103, 104]. Most cases of diarrhea were transient and mild to moderate in severity $[103,104]$.

Preclinical data from an animal model revealed that tenapanor effectively reduced phosphate absorption and facilitated a $50 \%$ reduction in phosphate binder dose [105]. In clinical trials, tenapanor has been evaluated for efficacy as monotherapy (vs. placebo) in separate trials of 12 and 52 weeks. At 12 weeks, tenapanor administration lowered serum phosphorus in subjects from baseline concentrations of $8.1 \mathrm{mg} / \mathrm{dL}$ to $5.5 \mathrm{mg} / \mathrm{dL}$ in the efficacy analysis set [77]. This phase 3, double-blinded, placebo-controlled randomized trial of tenapanor showed no clinically significant changes of sodium or potassium concentrations from baseline in patients on dialysis in the USA. [77]. Diarrhea, the most common adverse event, was observed in $30 \%, 41 \%$, and $48 \%$ of subjects receiving $3 \mathrm{mg}, 10 \mathrm{mg}$, and $30 \mathrm{mg}$ of tenapanor, respectively [77]. Softened stool and a modest increase in bowel movement frequency may be anticipated with tenapanor administration [77]. In the long-term phase 3 study, at 26 weeks, tenapanor administration lowered serum phosphorus in subjects from baseline concentrations of $7.7 \mathrm{mg} / \mathrm{dL}$ to 5.1 $\mathrm{mg} / \mathrm{dL}$ in the efficacy analysis set [106].

Tenapanor has also been investigated with phosphate binders as part of a dual mechanism approach to phosphorus lowering in a 4-week human study [107]. A significantly larger proportion of subjects treated with tenapanor and binders achieved serum phosphorus concentrations of $<5.5 \mathrm{mg} / \mathrm{dL}$ at week 1 ( $49 \%$ vs. $21 \%$; $p<0.001$ ), week 2 ( $41 \%$ vs. $24 \%$; $p=0.003$ ), week 3 ( $47 \%$ vs. $18 \%$; $p<0.001$ ), and week 4 ( $37 \%$ vs. $22 \%$; $p$ $=0.01)$ compared to those who only received binders [107]. An extension study evaluating the capacity of tenapanor to reduce serum phosphorus to within the normal range $(<4.5 \mathrm{mg} / \mathrm{dL})$ is ongoing (ClinicalTrials. gov: NCT03988920).

Nicotinamide is another potential treatment of hyperphosphatemia. This compound appears to inhibit gut NaPi2b cotransporters, thereby reducing phosphate-specific transcellular permeability [108]. Although intestinal NaPi2b-mediated cotransport of sodium and phosphate is responsible for $>90 \%$ of transcellular or active phosphate absorption in rats [59], the bulk of human phosphate absorption is passively mediated by the nonsaturable paracellular route [58]. Consequently, one could surmise that nicotinamide would be less efficacious than tenapanor as a treatment of hyperphosphatemia due to its lack of effect on paracellular phosphate absorption. This hypothesis is supported by the lack of significant reductions in phos- phorus or FGF23 in nondialysis CKD patients treated by lanthanum carbonate and/or nicotinamide during a 12-month trial [109].

\section{Future Studies}

Novel strategies that minimize the detrimental effects of hyperphosphatemia must also be explored in parallel. For example, it is possible that the harmful effects of high phosphorus concentrations are attributable to abnormalities in phosphate-sensing mechanisms [110]. Therefore, a greater understanding of phosphate regulatory and sensing mechanisms may provide insights into future methodologies that reduce the harmful effects of phosphorus overload [110].

\section{Conclusion}

Hyperphosphatemia in patients with CKD and ESRD remains a clinical challenge. Current therapeutic options are inadequate. Treatment choices beyond the dietary restriction of phosphate and phosphate binding are urgently needed. Innovations that directly inhibit phosphate absorption represent an advancement over conventional intestinal phosphate-binding strategies. Lowering paracellular phosphate absorption via intestinal NHE3 inhibition represents a novel mechanism that may have a greater quantitative effect on lowering serum phosphorus concentrations. Concomitant with a primary strategy of blocking phosphate absorption via the paracellular pathway, phosphate binders may be considered adjunctive therapy. Additional clinical trials in patients with CKD and ESRD assessing the efficacy of hyperphosphatemia treatments using both surrogate and hard patient-centered outcomes would be beneficial.

\section{Statement of Ethics}

For this review article, no new research study was conducted that prospectively assigns human participants or groups of humans to one or more health-related interventions, and therefore, no patients were enrolled or subjected to therapies. Thus, there are no requirements for any ethical approval or informed consent. The process of developing this article complies with internationally accepted standards for research practice and reporting. 


\section{Conflict of Interest Statement}

Dr. Yee is a paid consultant for Ardelyx, Inc. Dr. Jacobs and Dr. Rosenbaum are employees of Ardelyx, Inc. Dr. Sprague is a paid consultant for Ardelyx, Inc. Writing support is provided by Xelay Acumen Group and funded by Ardelyx, Inc. The authors have no other relevant affiliations or financial involvement with any organization or entity with a financial interest in or financial conflict with the subject matter or materials discussed in the manuscript apart from those disclosed.

\section{Funding Sources}

As a review article, there was no prospective study with patients or research study staff and therefore no funding needed.

\section{Author Contributions}

All authors participated in the review and screening of literature, conceptualization, writing, and revising of this review article.

\section{References}

1 Bansal VK. Serum inorganic phosphorus. 3rd ed. In: Walker HK, Hall WD, Hurst JW, editors. Clinical methods: the history, physical, and laboratory examinations. Boston: Butterworths; 1990.

2 Bellasi A, Kooienga L, Block GA. Phosphate binders: new products and challenges. Hemodial Int. 2006;10(3):225-34.

3 Walser M. Ion association. VI. Interactions between calcium, magnesium, inorganic phosphate, citrate and protein in normal human plasma. J Clin Invest. 1961;40(4):723-30.

4 Aldrich J. Phosphate disorders. In: Silverstein DC, Hopper K, editors. Small animal critical care medicine. Saint Louis: W.B. Saunders; 2009. p. 244-8.

5 Goyal R, Jialal I. Hyperphosphatemia. Treasure Island (FL): StatPearls Publishing; 2020.

6 McClure ST, Chang AR, Selvin E, Rebholz CM, Appel LJ. Dietary sources of phosphorus among adults in the United States: results from NHANES 2001-2014. Nutrients. 2017; 9(2):95.

7 Bohn L, Meyer AS, Rasmussen SK. Phytate: impact on environment and human nutrition. A challenge for molecular breeding. J Zhejiang Univ Sci B. 2008;9(3):165-91.

8 Lott JNA, Ockenden I, Raboy V, Batten GD. Phytic acid and phosphorus in crop seeds and fruits: a global estimate. Seed Sci Res. 2000; 10(1):11-33.

9 Iqbal TH, Lewis KO, Cooper BT. Phytase activity in the human and rat small intestine. Gut. 1994;35(9):1233-6.

10 Cupisti A, Kalantar-Zadeh K. Management of natural and added dietary phosphorus burden in kidney disease. Semin Nephrol. 2013; 33(2):180-90.

11 Hallberg L. Wheat fiber, phytates and iron absorption. Scand J Gastroenterol Suppl. 1987; 129:73-9.

12 Hurrell RF, Reddy MB, Juillerat MA, Cook JD. Degradation of phytic acid in cereal porridges improves iron absorption by human subjects. Am J Clin Nutr. 2003;77(5):1213-9.

13 Moe SM, Zidehsarai MP, Chambers MA Jackman LA, Radcliffe JS, Trevino LL, et al. Vegetarian compared with meat dietary protein source and phosphorus homeostasis in chronic kidney disease. Clin J Am Soc Nephrol. 2011;6(2):257-64.
14 Bell RR, Draper HH, Tzeng DY, Shin HK, Schmidt GR. Physiological responses of human adults to foods containing phosphate additives. J Nutr. 1977;107(1):42-50.

15 León JB, Sullivan CM, Sehgal AR. The prevalence of phosphorus-containing food additives in top-selling foods in grocery stores. J Ren Nutr. 2013;23(4):265-70.e2.

16 St-Jules DE, Goldfarb DS, Pompeii ML, Sevick MA. Phosphate additive avoidance in chronic kidney disease. Diabetes Spectr. 2017; 30(2):101-6.

17 Food Labeling: Revision of the Nutrition and Supplement Facts Labels. Food and Drug Administration; 2016.

18 Martínez Steele E, Popkin BM, Swinburn B, Monteiro CA. The share of ultra-processed foods and the overall nutritional quality of diets in the US: evidence from a nationally representative cross-sectional study. Popul Health Metrics. 2017;15(1):6.

19 Sullivan CM, Leon JB, Sehgal AR. Phosphorus-containing food additives and the accuracy of nutrient databases: implications for renal patients. J Ren Nutr. 2007;17(5):350-4.

20 Hutchison AJ, Smith CP, Brenchley PE. Pharmacology, efficacy and safety of oral phosphate binders. Nat Rev Nephrol. 2011;7(10):578-89.

21 Moshfegh AJ, Kovalchik AF, Clemens JC. Phosphorus intake of Americans, what we eat in America, NHANES 2011-2012. Worldwide Web Site: Food Surveys Research Group; 2016.

22 Institute of Medicine (US) Standing Committee on the Scientific Evaluation of Dietary Reference Intakes. Dietary reference intakes for calcium, phosphorus, magnesium, vitamin $\mathrm{D}$, and fluoride. Washington (DC): National Academies Press; 1997.

23 National Kidney Foundation. K/DOQI clinical practice guidelines for bone metabolism and disease in chronic kidney disease. Am J Kidney Dis. 2003;42(4 Suppl 3):S1S201.

24 Nelson SM, Sarabia SR, Christilaw E, Ward EC, Lynch SK, Adams MA, et al. Phosphate-containing prescription medications contribute to the daily phosphate intake in a third of hemodialysis patients. J Ren Nutr. 2017;27(2):91-6.

25 Sherman RA, Ravella S, Kapoian T. A dearth of data: the problem of phosphorus in prescription medications. Kidney Int. 2015; 87(6):1097-9.
26 Ramirez JA, Emmett M, White MG, Fathi N, Santa Ana CA, Morawski SG, et al. The absorption of dietary phosphorus and calcium in hemodialysis patients. Kidney Int. 1986; 30(5):753-9.

27 System USRD. 2020 USRDS Annual Data Report: Epidemiology of kidney disease in the United States. Bethesda, MD: National Institutes of Health, National Institute of Diabetes and Digestive and Kidney Diseases; 2020.

28 Craver L, Marco MP, Martínez I, Rue M, Borràs $\mathrm{M}$, Martín $\mathrm{ML}$, et al. Mineral metabolism parameters throughout chronic kidney disease stages 1-5: achievement of K/DOQI target ranges. Nephrol Dial Transplant. 2007; 22(4):1171-6.

29 Qadeer HA, Bashir K. Physiology, phosphate. Treasure Island, FL: StatPearls Publishing; 2020.

30 Walling MW. Intestinal Ca and phosphate transport: differential responses to vitamin D3 metabolites. Am J Physiol. 1977;233(6): E488-94.

31 Katai K, Miyamoto K, Kishida S, Segawa H, Nii T, Tanaka H, et al. Regulation of intestinal $\mathrm{Na}$-dependent phosphate co-transporters by a low-phosphate diet and 1,25-dihydroxyvitamin D3. Biochem J. 1999;343(Pt 3):705-12.

32 Hattenhauer O, Traebert M, Murer H, Biber $\mathrm{J}$. Regulation of small intestinal Na-P(i) type IIb cotransporter by dietary phosphate intake. Am J Physiol. 1999;277(4):G756-62.

33 Isakova T, Wahl P, Vargas GS, Gutiérrez OM, Scialla J, Xie H, et al. Fibroblast growth factor 23 is elevated before parathyroid hormone and phosphate in chronic kidney disease. Kidney Int. 2011;79(12):1370-8.

34 Saki F, Kassaee SR, Salehifar A, Omrani GHR. Interaction between serum FGF-23 and PTH in renal phosphate excretion, a case-control study in hypoparathyroid patients. BMC Nephrol. 2020;21(1):176.

35 Miyamoto K, Ito M, Kuwahata M, Kato S, Segawa H. Inhibition of intestinal sodium-dependent inorganic phosphate transport by fibroblast growth factor 23. Ther Apher Dial. 2005;9(4):331-5.

36 Phosphate binder use, last 3 months: DOPPS Practice Monitor; 2020. 
37 Goodman WG, Goldin J, Kuizon BD, Yoon C, Gales B, Sider D, et al. Coronary-artery calcification in young adults with end-stage renal disease who are undergoing dialysis. N Engl J Med. 2000;342(20):1478-83.

38 Slinin Y, Foley RN, Collins AJ. Calcium, phosphorus, parathyroid hormone, and cardiovascular disease in hemodialysis patients: the USRDS waves 1, 3, and 4 study. J Am Soc Nephrol. 2005;16(6):1788-93.

39 Cooper K, Quarles D, Kubo Y, Tomlin H, Goodman W. Relationship between reductions in parathyroid hormone and serum phosphorus during the management of secondary hyperparathyroidism with calcimimetics in hemodialysis patients. Nephron Clin Pract. 2012;121(3-4):c124-30.

40 Pazianas M, Miller PD. Current understanding of mineral and bone disorders of chronic kidney disease and the scientific grounds on the use of exogenous parathyroid hormone in its management. J Bone Metab. 2020;27(1):1-13.

41 Moe S, Drüeke T, Cunningham J, Goodman W, Martin K, Olgaard K, et al. Definition, evaluation, and classification of renal osteodystrophy: a position statement from Kidney Disease: Improving Global Outcomes (KDIGO). Kidney Int. 2006;69(11):1945-53.

42 Block GA, Kilpatrick RD, Lowe KA, Wang W Danese MD. CKD-mineral and bone disorder and risk of death and cardiovascular hospitalization in patients on hemodialysis. Clin J Am Soc Nephrol. 2013;8(12):2132-40.

43 Chuang SH, Wong HC, Vathsala A, Lee E, How PP. Prevalence of chronic kidney disease-mineral and bone disorder in incident peritoneal dialysis patients and its association with short-term outcomes. Singapore Med J. 2016;57(11):603-9.

44 Scialla JJ, Xie H, Rahman M, Anderson AH, Isakova $\mathrm{T}$, Ojo $\mathrm{A}$, et al. Fibroblast growth factor-23 and cardiovascular events in CKD. J Am Soc Nephrol. 2014;25(2):349-60.

45 Almqvist EG, Bondeson AG, Bondeson L, Nissborg A, Smedgård P, Svensson SE. Cardiac dysfunction in mild primary hyperparathyroidism assessed by radionuclide angiography and echocardiography before and after parathyroidectomy. Surgery. 2002;132(6): 1126-32; discussion 32.

46 Shang D, Xie Q, Ge X, Yan H, Tian J, Kuang $\mathrm{D}$, et al. Hyperphosphatemia as an independent risk factor for coronary artery calcification progression in peritoneal dialysis patients. BMC Nephrol. 2015;16(1):107.

47 Airy M, Schold JD, Jolly SE, Arrigain S, Bansal $\mathrm{N}$, Winkelmayer WC, et al. Cause-specific mortality in patients with chronic kidney disease and atrial fibrillation. Am J Nephrol. 2018;48(1):36-45.

48 Kestenbaum B, Sampson JN, Rudser KD, Patterson DJ, Seliger SL, Young B, et al. Serum phosphate levels and mortality risk among people with chronic kidney disease. J Am Soc Nephrol. 2005;16(2):520-8.
49 Zhong C, You S, Chen J, Zhai G, Du H, Luo Y, et al. Serum alkaline phosphatase, phosphate, and in-hospital mortality in acute ischemic stroke patients. J Stroke Cerebrovasc Dis. 2018;27(1):257-66.

50 Lopes MB, Karaboyas A, Bieber B, Pisoni RL, Walpen S, Fukagawa $M$, et al. Impact of longer term phosphorus control on cardiovascular mortality in hemodialysis patients using an area under the curve approach: results from the DOPPS. Nephrol Dial Transplant. 2020;35(10):1794-801.

51 Kidney Disease: Improving Global Outcomes (KDIGO) CKD-MBD Update Work Group. KDIGO 2017 Clinical Practice Guideline Update for the Diagnosis, Evaluation, Prevention, and Treatment of Chronic Kidney DiseaseMineral and Bone Disorder (CKD-MBD). Kidney Int Suppl (2011). 2017;7(1):1-59.

52 Serum phosphorus (most recent), categories: DOPPS Practice Monitor; 2020.

53 Sabbagh Y, Giral H, Caldas Y, Levi M, Schiavi SC. Intestinal phosphate transport. Adv Chronic Kidney Dis. 2011;18(2):85-90.

54 Shimada T, Hasegawa H, Yamazaki Y, Muto T, Hino R, Takeuchi Y, et al. FGF-23 is a potent regulator of vitamin $\mathrm{D}$ metabolism and phosphate homeostasis. J Bone Miner Res. 2004;19(3):429-35.

$55 \mathrm{McHardy}$ GJR, Parsons DS. The absorption of inorganic phosphate from the small intestine of the rat. Exp Physiol. 1956;41(4):398-409.

56 Walton J, Gray TK. Absorption of inorganic phosphate in the human small intestine. Clin Sci. 1979;56(5):407-12.

57 Danisi G, Straub RW. Unidirectional influx of phosphate across the mucosal membrane of rabbit small intestine. Pflugers Arch. 1980; 385(2):117-22.

58 Davis GR, Zerwekh JE, Parker TF, Krejs GJ, Pak CY, Fordtran JS. Absorption of phosphate in the jejunum of patients with chronic renal failure before and after correction of vitamin D deficiency. Gastroenterology. 1983; 85(4):908-16.

59 Sabbagh Y, O’Brien SP, Song W, Boulanger $\mathrm{JH}$, Stockmann A, Arbeeny C, et al. Intestinal npt $2 \mathrm{~b}$ plays a major role in phosphate absorption and homeostasis. J Am Soc Nephrol. 2009;20(11):2348-58.

60 Fordtran JS, Locklear TW. Ionic constituents and osmolality of gastric and small-intestinal fluids after eating. Am J Dig Dis. 1966;11(7): 503-21.

61 Taniguchi K, Terai K, Terada Y. Novel NaPiIIb inhibitor ASP3325 inhibits phosphate absorption in intestine and reduces plasma phosphorus level in rats with renal failure. J Am Soc Nephrol. 2015:FR-PO936.

62 Larsson TE, Kameoka C, Nakajo I, Taniuchi Y, Yoshida S, Akizawa T, et al. NPT-IIb inhibition does not improve hyperphosphatemia in CKD. Kidney Int Rep. 2018;3(1):73-80.

63 Saurette M, Alexander RT. Intestinal phosphate absorption: the paracellular pathway predominates? Exp Biol Med. 2019;244(8): 646-54.
64 Lee DB, Walling MW, Corry DB. Phosphate transport across rat jejunum: influence of sodium, $\mathrm{pH}$, and 1,25-dihydroxyvitamin $\mathrm{D} 3$. Am J Physiol. 1986;251(1 Pt 1):G90-5.

65 Knöpfel T, Himmerkus N, Günzel D, Bleich M, Hernando N, Wagner CA. Paracellular transport of phosphate along the intestine. Am J Physiol Gastrointest Liver Physiol. 2019; 317(2):G233-G41.

66 King AJ, Siegel M, He Y, Nie B, Wang J, KooMcCoy S, et al. Inhibition of sodium/hydrogen exchanger 3 in the gastrointestinal tract by tenapanor reduces paracellular phosphate permeability. Sci Transl Med. 2018;10(456): eaam6474.

67 Karp H, Ekholm P, Kemi V, Itkonen S, Hirvonen T, Närkki S, et al. Differences among total and in vitro digestible phosphorus content of plant foods and beverages. J Ren Nutr. 2012;22(4):416-22.

68 Marks J, Lee GJ, Nadaraja SP, Debnam ES Unwin RJ. Experimental and regional variations in $\mathrm{Na}+$-dependent and $\mathrm{Na}+$-independent phosphate transport along the rat small intestine and colon. Physiol Rep. 2015;3(1).

69 Vorland CJ, Biruete A, Lachcik PJ, Srinivasan S, Chen NX, Moe SM, et al. Kidney disease progression does not decrease intestinal phosphorus absorption in a rat model of chronic kidney disease-mineral bone disorder. J Bone Miner Res. 2020;35(2):333-42.

70 Dudeja PK, Rao DD, Syed I, Joshi V, Dahdal RY, Gardner C, et al. Intestinal distribution of human $\mathrm{Na}+/ \mathrm{H}+$ exchanger isoforms NHE-1, NHE-2, and NHE-3 mRNA. Am J Physiol. 1996;271(3 Pt 1):G483-93.

71 He P, Yun CC. Mechanisms of the regulation of the intestinal $\mathrm{Na}+/ \mathrm{H}+$ exchanger NHE3. J Biomed Biotechnol. 2010;2010:238080.

72 Gawenis LR, Stien X, Shull GE, Schultheis PI, Woo AL, Walker NM, et al. Intestinal $\mathrm{NaCl}$ transport in NHE2 and NHE3 knockout mice. Am J Physiol Gastrointest Liver Physiol. 2002;282(5):G776-84.

73 Schultheis PJ, Clarke LL, Meneton P, Miller ML, Soleimani M, Gawenis LR, et al. Renal and intestinal absorptive defects in mice lacking the NHE3 $\mathrm{Na}+/ \mathrm{H}+$ exchanger. Nat Genet. 1998;19(3):282-5.

74 Pan W, Borovac J, Spicer Z, Hoenderop JG, Bindels RJ, Shull GE, et al. The epithelial sodium/proton exchanger, NHE3, is necessary for renal and intestinal calcium (re)absorption. Am J Physiol Renal Physiol. 2012;302(8): F943-56.

75 Labonté ED, Carreras CW, Leadbetter MR, Kozuka K, Kohler J, Koo-McCoy S, et al. Gastrointestinal inhibition of sodium-hydrogen exchanger 3 reduces phosphorus absorption and protects against vascular calcification in CKD. J Am Soc Nephrol. 2015;26(5):113849.

76 Rosenbaum DP, Yan A, Jacobs JW. Pharmacodynamics, safety, and tolerability of the NHE3 inhibitor tenapanor: two trials in healthy volunteers. Clin Drug Investig. 2018; 38(4):341-51. 
77 Block GA, Rosenbaum DP, Yan A, Chertow GM. Efficacy and safety of tenapanor in patients with hyperphosphatemia receiving maintenance hemodialysis: a randomized phase 3 trial. J Am Soc Nephrol. 2019;30(4): 641-52.

78 Shaman AM, Kowalski SR. Hyperphosphatemia management in patients with chronic kidney disease. Saudi Pharm J. 2016;24(4): 494-505.

79 Hou SH, Zhao J, Ellman CF, Hu J, Griffin Z, Spiegel DM, et al. Calcium and phosphorus fluxes during hemodialysis with low calcium dialysate. Am J Kidney Dis. 1991;18(2):21724.

80 DeSoi CA, Umans JG. Phosphate kinetics during high-flux hemodialysis. J Am Soc Nephrol. 1993;4:1214-8.

81 Umeukeje EM, Mixon AS, Cavanaugh KL. Phosphate-control adherence in hemodialysis patients: current perspectives. Patient Prefer Adherence. 2018;12:1175-91.

82 St-Jules DE, Rozga MR, Handu D, Carrero JJ. Effect of phosphate-specific diet therapy on phosphate levels in adults undergoing maintenance hemodialysis. A Syst Rev Meta-Anal. 2021;16(1):107-20.

83 Shinaberger CS, Greenland S, Kopple JD, Van Wyck D, Mehrotra R, Kovesdy CP, et al. Is controlling phosphorus by decreasing dietary protein intake beneficial or harmful in persons with chronic kidney disease? Am J Clin Nutr. 2008;88(6):1511-8

84 Rufino M, de Bonis E, Martín M, Rebollo S, Martín B, Miquel R, et al. Is it possible to control hyperphosphataemia with diet, without inducing protein malnutrition? Nephrol Dial Transplant. 1998;13(Suppl 3):65-7.

85 Dai L, Mukai H, Lindholm B, Heimbürger O, Barany P, Stenvinkel P, et al. Clinical global assessment of nutritional status as predictor of mortality in chronic kidney disease patients. PLoS One. 2017;12(12):e0186659.

86 Kang SS, Chang JW, Park Y. Nutritional Status Predicts 10-Year Mortality in Patients with End-Stage Renal Disease on Hemodialysis. Nutrients. 2017;9(4).

87 Fresenius Medical Care North America. Pho$\mathrm{sLo}^{\circ}$ gelcaps (calcium acetate): $667 \mathrm{mg}$ [prescribing information]. Waltham, MA: Fresenius Medical Care North America; 2011.

88 Fresenius Medical Care North America. VEL$\mathrm{PHORO}^{\circ}$ (sucroferric oxyhydroxide) [prescribing information]. Waltham, MA: Fresenius Medical Care North America; 2013.
89 Shire US Inc. FOSRENAL ${ }^{\circ}$ (lanthanum carbonate) [prescribing information]. Lexington, MA: Shire US Inc.; 2016.

90 Keryx Biopharmaceuticals Inc. AURYXIA (ferric citrate) tablets [prescribing information]. Cambridge, MA: Keryx Biopharmaceuticals Inc.; 2017.

91 Genzyme Corp. RENVELA (sevelamer carbonate) [prescribing information] Cambridge, MA: Genzyme Corp.; 2020.

92 Spherix Global Insights. RealWorld Dynamix: Dialysis. US: Spherix Global Insights; 2019. Available from: https://www.spherixglobalinsights.com/reports/nephrology-reports/dialysis-us/.

93 Bover Sanjuán J, Navarro-González JF, Arenas MD, Torregrosa JV, Tamargo Menéndez J, de Francisco ALM, et al. Pharmacological interactions of phosphate binders. Nefrologia. 2018;38(6):573-8.

94 Chiu YW, Teitelbaum I, Misra M, de Leon EM, Adzize T, Mehrotra R. Pill burden, adherence, hyperphosphatemia, and quality of life in maintenance dialysis patients. Clin J Am Soc Nephrol. 2009;4(6):1089-96.

95 KDOQI Work Group. KDOQI Clinical Practice Guideline for Nutrition in Children with CKD: 2008 update. Executive summary. Am J Kidney Dis. 2009;53(3 Suppl 2): S11-104.

96 Daugirdas JT, Finn WF, Emmett M, Chertow GM. The phosphate binder equivalent dose. Semin Dial. 2011;24(1):41-9.

97 Martin P, Wang P, Robinson A, Poole L, Dragone J, Smyth M, et al. Comparison of dietary phosphate absorption after single doses of lanthanum carbonate and sevelamer carbonate in healthy volunteers: a balance study. Am J Kidney Dis. 2011;57(5):700-6.

98 Mai ML, Emmett M, Sheikh MS, Santa Ana CA, Schiller L, Fordtran JS. Calcium acetate, an effective phosphorus binder in patients with renal failure. Kidney Int. 1989;36(4): 690-5.

99 Schiller LR, Santa Ana CA, Sheikh MS, Emmett M, Fordtran JS. Effect of the time of administration of calcium acetate on phosphorus binding. N Engl J Med. 1989; 320(17):1110-3.

100 Sheikh MS, Maguire JA, Emmett M, Santa Ana CA, Nicar MJ, Schiller LR, et al. Reduction of dietary phosphorus absorption by phosphorus binders. A theoretical, in vitro, and in vivo study. J Clin Invest. 1989;83(1): 66-73.

101 Pratt R, Martin P, Poole L, Dragone J. 238: reduction of dietary phosphorus absorption with lanthanum carbonate or sevelamer carbonate: a balance study. Am J Kidney Dis. 2010;55.
102 Johansson S, Rosenbaum DP, Knutsson M, Leonsson-Zachrisson M. A phase 1 study of the safety, tolerability, pharmacodynamics, and pharmacokinetics of tenapanor in healthy Japanese volunteers. Clin Exp Nephrol. 2017;21(3):407-16.

103 Chey WD, Lembo AJ, Rosenbaum DP. Tenapanor treatment of patients with constipation-predominant irritable bowel syndrome: a phase 2, randomized, placebocontrolled efficacy and safety trial. Am J Gastroenterol. 2017;112(5):763-74.

104 Chey WD, Lembo AJ, Rosenbaum DP. Efficacy of tenapanor in treating patients with irritable bowel syndrome with constipation: a 12-Week, Placebo-Controlled Phase 3 Trial (T3MPO-1). Am J Gastroenterol. 2020; 115(2):281-93.

105 King AJ, Kohler J, Fung C, Jiang Z, Quach A, Kumaraswamy $\mathrm{P}$, et al. Combination treatment with tenapanor and sevelamer synergistically reduces urinary phosphorus excretion in rats. Am J Physiol-Renal Physiol. 2021;320(1):F133-44

106 Chertow GM, Yang Y, Rosenbaum DP. Long-term safety and efficacy of tenapanor for the control of serum phosphorus in patients with chronic kidney disease on dialysis. Am Soc Nephrol Kidney Week. 2021. October 22-25; Virtual 2020.

107 Pergola PE, Rosenbaum DP, Yang Y, Chertow GM. A randomized trial of tenapanor and phosphate binders as a dual-mechanism treatment for hyperphosphatemia in patients on maintenance dialysis (AMPLIFY). J Am Soc Nephrol. 2021;32(6):146573.

108 Eto N, Miyata Y, Ohno H, Yamashita T. Nicotinamide prevents the development of hyperphosphataemia by suppressing intestinal sodium-dependent phosphate transporter in rats with adenine-induced renal failure. Nephrol Dial Transplant. 2005; 20(7):1378-84.

109 Ix JH, Isakova T, Larive B, Raphael KL, Raj DS, Cheung AK, et al. Effects of nicotinamide and lanthanum carbonate on serum phosphate and fibroblast growth Factor-23 in CKD: the COMBINE trial. J Am Soc Nephrol. 2019;30(6):1096-108.

110 Michigami T, Kawai M, Yamazaki M, Ozono K. Phosphate as a signaling molecule and its sensing mechanism. Physiol Rev. 2018; 98(4):2317-48. 